\title{
Necessity for Vitamin D Screening among Urban Bedouin Women of Childbearing Age
}

\author{
Inna Rudoy1,2, Ilia Volkov1,2* \\ ${ }^{1}$ Department of Family Medicine, Sial Research Center for Family Medicine and Primary Care, Faculty of Health \\ Sciences, Ben-Gurion University of the Negev, Beer-Sheva, Israel \\ ${ }^{2}$ Clalit Health Services, Southern District, Beer-Sheva, Israel \\ Email: ${ }^{*}$ iliavolkovmd@gmail.com
}

Received 8 April 2015; accepted 10 May 2015; published 13 May 2015

Copyright (C) 2015 by authors and Scientific Research Publishing Inc.

This work is licensed under the Creative Commons Attribution International License (CC BY). http://creativecommons.org/licenses/by/4.0/

(c) $\underset{\mathrm{EY}}{\mathrm{EP}}$ Open Access

\begin{abstract}
Vitamin D (Vit D) plays multiple roles in bodily functions. Vit D deficiency is a common, but often under-diagnosed condition with possible serious complications. According to some research, Vit D is important particularly among women and children. No data were found concerning the Vit D status among urban Bedouin women of childbearing age. The research study is retrospective and descriptive. We analyzed 202 medical histories of patients undergoing blood tests for Vit D level for various reasons. The main objectives of the research were: 1) determining the prevalence of the Vit D deficiency among the Bedouin women of childbearing age; 2) identifying the causes for the physicians' reasons for suspecting Vit D deficiency: the complaints or symptoms which cause the doctor to test for Vit $D$ level. As a result, in $80.7 \%$ of those tested for Vit $D$, levels were less than $10 \mathrm{ng} / \mathrm{ml}$, and in $19.3 \%$, levels of 10 to $20 \mathrm{ng} / \mathrm{ml}$ were found. In lieu of our findings and in order to prevent serious health problems, Vit D screening plan should be seriously considered and discussed in the Bedouin population with high risk of deficiency.
\end{abstract}

\section{Keywords}

Vitamin D, Vitamin D Deficiency, Vitamin D Deficiency in Women, Prevalence of Vitamin D Deficiency, Bedouin Population

\section{Introduction}

Vitamin D (Vit D) has multiple roles in human health. Vit D deficiency is a common, but often under-diagnosed condition with serious complications. Deficiency is predominantly common in the geriatric population, and has

${ }^{*}$ Corresponding author. 
been associated with increased risk of musculoskeletal, neuropsychiatric, cardiovascular, endocrine and oncologic disease. Although the morbidity of Vit D deficiency is well known in the elderly and among children, physicians are unlikely to consider it as a diagnosis in young adults, even when it is symptomatic [1]. Generally, Vit $\mathrm{D}$ is obtained through exposure to UVB radiation in the form of sunlight and cutaneous Vit D production. The season, sun avoidance, sunscreen protection and types of cultural dress can all limit vitamin D production [2].

The endocrine society clinical practice guideline recommends that clinicians screen for Vit D deficiency in people at risk for deficiency, such as obese individuals, blacks, pregnant and lactating women, patients treated with certain medications (anticonvulsant, glucocorticoids, antifungals such as ketoconazole) and patients with malabsorption syndromes. There are no guidelines for screening individuals who are not at risk [3]. According to some research studies, Vit D is particularly important for women and children [4]-[6].

A comprehensive MEDLINE search was conducted. No data were found concerning the Vit D status among urban Bedouin women of childbearing age.

The objectives of the research:

1) Determining the prevalence of the Vitamin D deficiency among the Bedouin women of childbearing age in an urban population of one family doctor practice in Southern Israel.

2) Identifying the causes for the physicians' reasons for testing Vit D levels in the blood, such as the complaints or symptoms causing the doctor to suspect Vit D deficiency.

3) Identifying diseases associated to Vit D deficiency in our sample, comparing them to the known data given in the literature.

\section{Research Methods and Structure}

The research study is retrospective and descriptive.

\subsection{Study Population}

Urban Bedouin women who receive medical care service in one family-physician practice in the "Clalit Health Services" Clinic, in Rahat, the largest Bedouin town in Israel. This clinic serves low-income population. In the practice there are about 1800 patients, among them 652 women, childbearing ages of 20 - 50 years old. The study population included women who from 2008 up to 2011 had undergone at least one blood test for Vit D level that was measured by a diasorin 25-OH-D assay.

\subsection{Method for Gathering Information}

A report of all patients was extracted from the medical computerized information system (“Clicks”). We analyzed 202 medical histories of patients undergoing blood tests for Vit D level for various reasons (pain of extremities, general pain, headache, paresthesias, fatigue, dizziness, sleep disturbance, decrease in memory, mood fluctuations, etc.).

\subsection{Statistical Analysis}

Data were analyzed using SPSS 17 software. Frequencies were used to describe categorical variables. Mean, standard deviation and median were used to describe continuous variables. In order to compare statistically significant differences between patients' different vitamin D levels, Chi-square tests were performed. $\mathrm{P}<0.05$ was considered statistically significant.

\section{Results}

Median age was 37 years old. Most of them were multipara (Table 1). Musculoskeletal pain was the major complaint (49.8\%). The group of neuro-psychiatric diseases associated to Vit D deficiency was slightly more (12.9\%) than other conditions (Table 2). In $80.7 \%$ of study population levels of Vit D were less than $10 \mathrm{ng} / \mathrm{ml}$, and in the rest of the population (19.3\%) the levels were between 10 to $20 \mathrm{ng} / \mathrm{ml}$ (Figure 1).

\section{Discussion}

In our research we found very low levels of Vit D in study population, along with different features or symp- 
Table 1. Characteristics of the study’s population.

\begin{tabular}{lcccc}
\hline & Mean $( \pm \mathbf{s d})$ & Median & Range & N (\%) \\
\hline Age & $36.84 \pm 8.292$ & 37 & $20-52$ & 202 \\
BMI & $27.47 \pm 5.772$ & 26.9 & $16-55$ & 201 \\
Number of springs under 18 years & $5.04 \pm 3.581$ & 5 & $0-15$ & 202 \\
Number of visits to the clinic in the last year & $8.78 \pm 5.467$ & 8 & $1-30$ & $56(28 \%)$ \\
Skin color & & & 127 (63\%) \\
$\quad$ White & & & 19 (9\%) \\
$\quad$ Intermediate & & & $5(2.5 \%)$ \\
$\quad$ Black & & & 197 (97.5\%) \\
Face veil & & & \\
$\quad$ Yes & & & \\
$\quad$ No & & & \\
\hline
\end{tabular}

Table 2. Medical complains and diseases.

\begin{tabular}{|c|c|c|c|}
\hline Complains & $\mathbf{N}$ & $\%$ & Missing \\
\hline Backache, arthralgia & 100 & $49.8 \%$ & 3 \\
\hline General pain & 57 & $28.4 \%$ & 3 \\
\hline Other & 54 & $26.7 \%$ & 2 \\
\hline Dizziness & 48 & $23.8 \%$ & 2 \\
\hline Headache & 47 & $23.3 \%$ & 2 \\
\hline Fatigue & 45 & $22.3 \%$ & 2 \\
\hline Prox. weakness & 30 & $14.9 \%$ & 2 \\
\hline Insomnia & 6 & $3.0 \%$ & 2 \\
\hline Recurring falls & 2 & $1.0 \%$ & 2 \\
\hline Diseases & $\mathbf{N}$ & $\%$ & Missing \\
\hline Neuro-Psych. D-S & 26 & $12.9 \%$ & 2 \\
\hline Musc.-Scel. D-S & 18 & $8.9 \%$ & 2 \\
\hline Autoimmune D-S & 12 & $6.0 \%$ & 3 \\
\hline Hypertension & 10 & $5.0 \%$ & 2 \\
\hline Diabetes mell. & 9 & $4.5 \%$ & 3 \\
\hline Malabsorption sdms & 8 & $4.0 \%$ & 2 \\
\hline Malignancy & 6 & $3.0 \%$ & 3 \\
\hline Asthma & 5 & $2.5 \%$ & 2 \\
\hline Chr. medications using & 4 & $2.0 \%$ & 2 \\
\hline Fractures & 3 & $1.5 \%$ & 3 \\
\hline
\end{tabular}




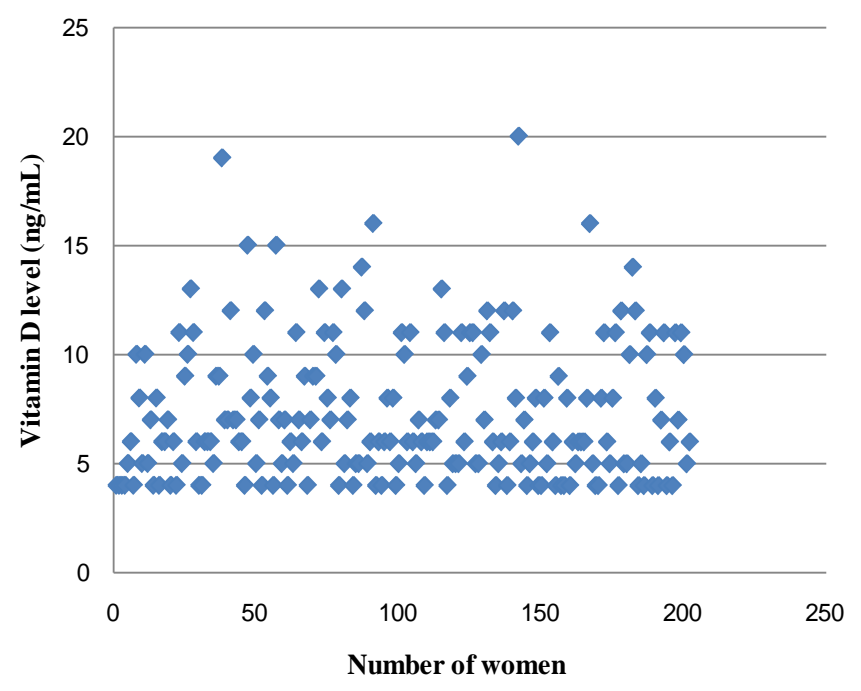

Figure 1. Levels of Vitamin D.

toms of vitamin D deficiency in the majority of women. Any of the surveyed patients had no normal or close to normal Vit D level. When we started to elucidate the phenomenon, we understood that we have more questions than answers: How can this phenomenon be explained? How does it influence the wellbeing of the women? What is the kind of problems we should anticipate in the future?

The list of organs and body systems in which Vit D plays a functional role is constantly increased. The precise role of low Vit D in the pathogenesis of some diseases is unclear. There are many controversies in current literature whether the associations are causal or due to confounding [7]-[10].

We did not find an association between low Vit D and specific diseases or malignancy. Possibly this lack of association can be explained by the relatively young age of women or by the small sample size. A majority of women suffered from different kinds of pain (pain of limbs, general pain, headache, etc.). Possibly this presentation among patients with these complains might be an additional guideline for primary physicians to check levels of Vit D in high risk population such as ours. Some research's investigated connection between fibromyalgia and Vit D, and didn't find association between low level of vitamin D and a fibromyalgia [11]. This investigation did not show any direct connection between low levels of Vit D to obesity, skin color, or wearing a face cover. In addition, correlation between frequency of visits to the clinic and the number of complains was not significant (Table 3). We suppose that very low level of Vit D in Bedouin population is combined with a number of sociodemographic factors and lifestyle. Radical changes in lifestyle resulted from urbanization of the Bedouin population, as well as exposure to modern lifestyle. The population of Bedouins in the Negev is about 260,000 , half of whom live in the city of Rahat, the other little towns and villages. The rest live in non-recognized rural communities. The Bedouins are desert people, but the ancient traditional lifestyle led by the Bedouin people is disappearing, pushed aside by the modern lifestyle of the western world, bringing to an end the nomadic life of the Negev Bedouins. Bedouin women in Israel typically marry young and raise large families. Having an average of five children gives them a strong identity as a mother and homemaker, along with great self esteem and social standing. The urbanization process has lead to a significant drop in the level of physical activity, outdoor activity, changes in food consumption patterns, uptake of large amounts of phytates by eating unleavened bread that can lead to violation of level of calcium and Vit D [12], and limited exposure to sunlight as a result of their traditional, extensive clothing. These factors play an important role in our results of prominent Vit D deficiency in this population.

\section{Conclusion}

In lieu of our findings and in order to prevent serious health problems, Vit D screening plan should be seriously considered and discussed among those servicing this population with high risk of deficiency. No doubt, that even very low-level Vit D deficiency can be indicative of disturbances which can be prevented or reversed by 
Table 3. Characteristics of the women by levels of vitamin D.

\begin{tabular}{|c|c|c|c|c|c|}
\hline & \multicolumn{4}{|c|}{ Level of Vitamin D } & \multirow{3}{*}{$P$ value } \\
\hline & \multicolumn{2}{|c|}{10 or less $(N=163)$} & \multicolumn{2}{|c|}{ More than $10(\mathrm{~N}=39)$} & \\
\hline & $\mathbf{N}$ & $\%$ & $\mathbf{N}$ & $\%$ & \\
\hline \multicolumn{6}{|c|}{$\begin{array}{l}\text { Number of visits to the clinic } \\
\text { in the last year }\end{array}$} \\
\hline $0-6$ & 75 & $46.0 \%$ & 10 & $26.3 \%$ & \\
\hline \multirow[t]{2}{*}{$7+$} & 88 & $54.0 \%$ & 28 & $73.7 \%$ & 0.02 \\
\hline & 163 & & 38 & & \\
\hline \multicolumn{6}{|l|}{ BMI } \\
\hline Less than 27 & 78 & $47.9 \%$ & 23 & $60.5 \%$ & \\
\hline \multirow[t]{2}{*}{$27+$} & 85 & $52.1 \%$ & 15 & $39.5 \%$ & 0.11 \\
\hline & 163 & & 38 & & \\
\hline \multicolumn{6}{|c|}{ Number of complaints } \\
\hline $0-2$ & 125 & $76.7 \%$ & 30 & $78.9 \%$ & \\
\hline \multirow[t]{2}{*}{$3+$} & 38 & $23.3 \%$ & 8 & $21.1 \%$ & 0.476 \\
\hline & 163 & & 38 & & \\
\hline \multicolumn{6}{|l|}{ Skin color } \\
\hline White & 47 & $28.8 \%$ & 9 & $23.1 \%$ & \\
\hline Intermediate & 101 & $62.0 \%$ & 26 & $66.7 \%$ & 0.769 \\
\hline \multirow[t]{2}{*}{ Black } & 15 & $9.2 \%$ & 4 & $10.3 \%$ & \\
\hline & 163 & & 39 & & \\
\hline
\end{tabular}

early diagnosis and prompt medical treatment. More extensive research investigations should substantiate our findings.

\section{References}

[1] Belaid, S., Martin, A., Schott, A.M., Laville, M. and Le Goaziou, M.F. (2008) Hypovitaminosis D among 18-to-49Year-Old Women Wearing Concealing Clothes, an Ignored Reality in General Practice. La Presse Médicale, 37, 201206. http://dx.doi.org/10.1016/j.lpm.2007.06.024

[2] Kennel, K.A., Drake, M.T. and Hurley, D.L. (2010) Vitamin D Deficiency in Adults: When to Test and How to Treat. Mayo Clinic Proceedings, 85, 752-757. http://dx.doi.org/10.4065/mcp.2010.0138

[3] Holick, M.F., Binkley, N.C., Bischoff-Ferrari, H.A., Gordon, C.M., Hanley, D.A., Heaney, R.P., Murad, M.H. and Weaver, C.M., Endocrine Society (2011) Evaluation, Treatment, and Prevention of Vitamin D Deficiency: An Endocrine Society Clinical Practice Guideline. Journal of Clinical Endocrinology Metabolism, 96, 1911-1930. http://dx.doi.org/10.1210/jc.2011-0385

[4] Thandrayen, K. and Pettifor, J.M. (2012) Maternal Vitamin D Status: Implications for the Development of Infantile Nutritional Rickets. Rheumatic Disease Clinics of North America, 38, 61-79. http://dx.doi.org/10.1016/j.rdc.2012.03.007

[5] Fedirko, V., Torres-Mejía, G., Ortega-Olvera, C., Biessy, C., Angeles-Llerenas, A., Lazcano-Ponce, E., Saldaña-Quiroz, V.A. and Romieu, I. (2012) Serum 25-Hydroxyvitamin D and Risk of Breast Cancer: Results of a Large Population-Based Case-Control Study in Mexican Women. Cancer Causes Control, 23, 1149-1162. http://dx.doi.org/10.1007/s10552-012-9984-z

[6] Hobbs, R.D., Habib, Z., Alromaihi, D., Idi, L., Parikh, N., Blocki, F. and Rao, D.S. (2009) Severe Vitamin D Deficiency in Arab-American Women Living in Dearborn, Michigan. Endocrine Practice, 15, 35-40. 
http://dx.doi.org/10.4158/EP.15.1.35

[7] de Boer, I.H., Levin, G., Robinson-Cohen, C., Biggs, M.L., Hoofnagle, A.N., Siscovick, D.S. and Kestenbaum, B. (2012) Serum 25-Hydroxyvitamin D Concentration and Risk for Major Clinical Disease Events in a Community-Based Population of Older Adults: A Cohort Study. Annals of Internal Medicine, 156, 627-634.

http://dx.doi.org/10.7326/0003-4819-156-9-201205010-00004

[8] Eyles, D.W., Burne, T.H. and McGrath, J.J. (2012) Vitamin D, Effects on Brain Development, Adult Brain Function and the Links between Low Levels of Vitamin D and Neuropsychiatric Disease. Frontiers in Neuroendocrinology, 34, 47-64. http://dx.doi.org/10.1016/j.yfrne.2012.07.001

[9] Thorne-Lyman, A. and Fawzi, W.W. (2012) Vitamin D during Pregnancy and Maternal, Neonatal and Infant Health Outcomes: A Systematic Review and Meta-Analysis. Paediatric and Perinatal Epidemiology, 26, 75-90. http://dx.doi.org/10.1111/j.1365-3016.2012.01283.x

[10] Jääskeläinen, T., Knekt, P., Marniemi, J., Sares-Jäske, L., Männistö, S., Heliövaara, M. and Järvinen, R. (2012) Vitamin D Status Is Associated with Sociodemographic Factors, Lifestyle and Metabolic Health. European Journal of Nutrition, 52, 513-525. http://dx.doi.org/10.1007/s00394-012-0354-0

[11] Tandeter, H., Grynbaum, M., Zuili, I., Shany, S. and Shvartzman, P. (2009) Serum 25-OH Vitamin D Levels in Patients with Fibromyalgia. Israel Medical Association Journal, 11, 339-342.

[12] Sasson, A., Etzion, Z., Shany, S., Berlyne, G.M. and Yagil, R. (1982) Growth and Bone Mineralisation as Affected by Dietary Calcium, Phytic Acid and Vitamin D. Comparative Biochemistry and Physiology A: Comparative Physiology, 72, 43-48. http://dx.doi.org/10.1016/0300-9629(82)90008-1 